\title{
Luminescent and Magnetic Properties of $\mathrm{Fe}_{3} \mathrm{O}_{4} @ \mathrm{SiO}_{2}$ :phen:Eu ${ }^{3+}$
}

\author{
Raphael Lucas de Sousa Silva ${ }^{a}$, Alberthmeiry Teixeira de Figueiredo ${ }^{a *,}$ Cristiano Morita Barrado ${ }^{a}$, \\ Marcelo Henrique Sousa ${ }^{b}$
}

${ }^{a}$ Departamento de Química, Universidade Federal de Goiás, Catalão, GO, Brazil

${ }^{b}$ Faculdade de Ceilândia, Universidade de Brasília, Ceilândia, Brasília, DF, Brazil

Received: November 09, 2016; Revised: May 26, 2017; Accepted: July 03, 2017

\begin{abstract}
Magnetite was doped with rare earth ions (europium) to produce core-shell materials with both magnetic and luminescent properties, i.e., a magnetic $\mathrm{Fe}_{3} \mathrm{O}_{4}$ oxide core and $\mathrm{SiO}_{2}$ :phen: $\mathrm{Eu}^{3+}$ shell. The resulting material was analyzed by X-ray powder diffraction and transmission electron microscopy, and subjected to magnetic and luminescence emission measurements. All the synthesized materials exhibited superparamagnetic behavior and luminescence emission. The magnetic behavior of $\mathrm{Fe}_{3} \mathrm{O}_{4}$ and luminescence emission of $\mathrm{SiO}_{2}$ : $\mathrm{phen}: \mathrm{Eu}^{3+}$ of the materials were compared to precursors.
\end{abstract}

Keywords: magnetite, $\mathrm{Fe}_{3} \mathrm{O}_{4}$, core@shell, luminescence, Eu ${ }^{3+}$

\section{Introduction}

In recent years, the synthesis of magnetic iron oxide nanoparticles (particularly magnetite - $\mathrm{Fe}_{3} \mathrm{O}_{4}$ ) has been intensively explored with a view to biomedical applications such as targeted drug delivery, magnetic resonance imaging (MRI), and magnetic hyperthermia ${ }^{1-8}$.

Multifunctional materials are attractive because they may combine properties, which allow manipulation chemical functionalities, playing a key role in different applications. The use of multifunctional materials will, and in some cases already do, allow savings in number of parts, reducing the need for joining operations ${ }^{9}$. Moreover, materials that present both magnetic and luminescent properties have been developed $\mathrm{d}^{10-14}$ and applied to biotechnological processes such as imaging, tracking, and separation of biological molecules or cells ${ }^{15-19}$. One way to obtain both properties in a single multifunctional material is by using the core-shell strategy, which involves coating $\mathrm{Fe}_{3} \mathrm{O}_{4}$ nanoparticles with an actively fluorescent material, resulting in a system with magnetic and luminescent properties ${ }^{16,20-22}$. Thus, since lanthanide ions $\left(\mathrm{Ln}^{3+}\right)$ have important applications in fluorescent materials, electroluminescent devices and fluorescent probes for biological systems, they can be used as sources of fluorescence in multifunctional magnetic materials ${ }^{16,18-22}$. In fact, they have Laporte forbidden intraconfigurational $f-f$ transitions, and therefore present low absorption intensities. Organic ligands can be used as light collectors (antenna effect). 1,10-phenanthroline or its derivatives have been used as "antennas" of near-UV radiations in $\mathrm{Eu}^{3+}$ complexes due to their efficient ligand-to-lanthanide intracomplex energy transfer. The emission enhancement in the sample containing 1,10-phenanthroline is due to that the excitation energy is absorbed by this molecule and then occurs an efficient energy transfer from its triplet state to the $\mathrm{Eu}^{3+}$ ions. This excitation process is more efficient that the direct excitation, since the lanthanide cations are characterized by very low absorption coefficients ${ }^{23}$.

In core-shell systems, silica is a common capping material, since it is chemically inert, biocompatible, optically transparent and does not affect reactions at the core surface. Furthermore, coating with silica protects magnetite core particles and the luminescent probes can be dispersed on $\mathrm{it}^{6,20,24}$.

It has been proven that the $\mathrm{Fe}_{3} \mathrm{O}_{4}$ will greatly decrease the luminescence of $\mathrm{Eu}^{3+}$ ion if they are directly blended with them. Therefore, the $\mathrm{Eu}^{3+}$ should be effectively isolated to avoid direct contact with $\mathrm{Fe}_{3} \mathrm{O}_{4}$ if the strong luminescence of the magnetic-fluorescent bifunctional is to be achieved ${ }^{13}$. Thus, Core/shell structure reduces the interaction of the earthrare ion with the magnetic material. This work involved the synthesis of a magnetic-luminescent core-shell nanocomposite (Fig. 1). The magnetite core was coated with a luminescent silica $\left(\mathrm{SiO}_{2}: \mathrm{Eu}^{3+}\right)$ shell.

\section{Materials and Methods}

All the chemicals were of higher than $99.9 \%$ purity and were used as received. Magnetite nanoparticles were obtained by the coprecipitation of $\mathrm{Fe}^{3+}\left(\mathrm{FeCl}_{3} \cdot 6 \mathrm{H}_{2} \mathrm{O}\right)$ and $\mathrm{Fe}^{2+}\left(\mathrm{FeSO}_{4} \cdot 7 \mathrm{H}_{2} \mathrm{O}\right)$ salts (molar ratio of 2:1) in an alkaline medium $(\mathrm{pH}=11)$, using an adapted version of a procedure described elsewhere ${ }^{25}$. The overall reaction can be written as equation 1:

$$
\mathrm{Fe}^{3+}+2 \mathrm{Fe}^{2+}+8 \mathrm{OH}^{-} \rightarrow \mathrm{Fe}_{3} \mathrm{O}_{4}+4 \mathrm{H}_{2} \mathrm{O}
$$




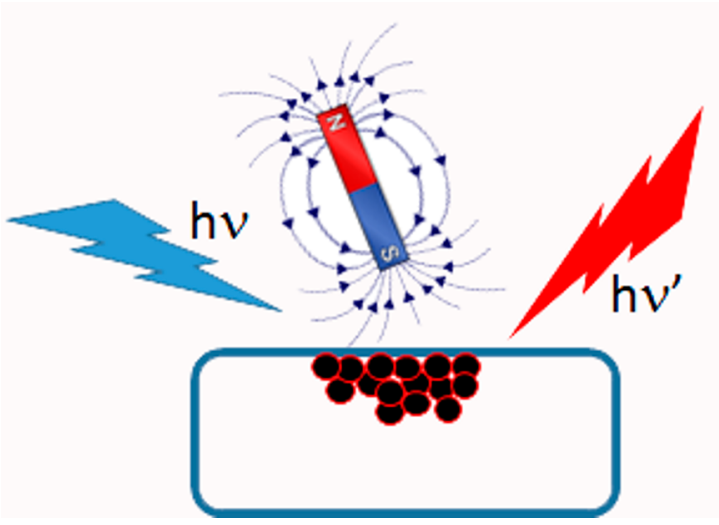

Figure 1. Magnetic materials that emit luminescence.

To produce the core-shell nanocomposites, appropriate amounts of tetraethylorthosilicate, phenanthroline and europium(III) were dissolved in $20 \mathrm{~mL}$ of oxygen-free ethanol. Then, $1 \mathrm{~g}(0.0043 \mathrm{~mol})$ of $\mathrm{Fe}_{3} \mathrm{O}_{4}$ was added and the system was mixed for $30 \mathrm{~min}$. The precipitate was then washed several times in ethanol and dried at room temperature.

Table 1 describes the composition of the synthesized samples. The composition of the core consists solely of $\mathrm{Fe}_{3} \mathrm{O}_{4}$ while that of the shell comprises solely $\mathrm{SiO}_{2}:$ phen:Eu ${ }^{3+}$. Sample Fe-Si-1 contains primary proportion of the core and shell compositions; the samples Fe-Si-2 and Fe-Si-3 were obtained by variation in the layer thickness or concentration of $\mathrm{Eu}^{3+}$ ions. In all samples the molar ratio of phen and $\mathrm{Eu}^{3+}$ was set to be $4: 1$ as used by Liu and co-authors ${ }^{26}$ to produce a high luminescent nanocomposite.

To determine their structural characteristics, the powders were characterized by X-ray powder diffraction (XRD) in a Shimadzu XRD 6100 diffractometer, using $\mathrm{CuKa}(\mathrm{k}=$ $1.5406 \AA$ ) radiation. The data were collected in fixed-time mode, from $10^{\circ}$ to $80^{\circ}$ in the $2 \theta$ range, using a divergence slit of $0.5^{\circ}$ and receiving slit of $0.3 \mathrm{~mm}$ and a step size of $0.02^{\circ}$. Microstructural and morphological analyses were performed by field emission scanning electron microscopy (FESEM, Zeiss Supra 35), using 2 to $4 \mathrm{kV}$ under different levels of magnification. The powders were examined by transmission electron microscopy (TEM) in a JEOL 3010 ARP microscope operating at an accelerating voltage of $300 \mathrm{kV}$. The room temperature nanoparticle magnetization characterization was obtained using a vibrating sample magnetometer Lakeshore model 7300. The PL measurements were taken using a Jarrell-Ash MonoSpec 27 monochromator and a Ge photodetector coupled to a data acquisition system composed of a microcomputer-controlled SR530 lock-in amplifier. The $350.7 \mathrm{~nm}$ excitation wavelength of a krypton ion laser (Coherent Innova) was used, with the laser output kept at $200 \mathrm{~mW}$.

All the measurements were taken at room temperature.

\section{Results and Discussion}

Fig. 2 shows the X-ray diffraction patterns of all the samples.

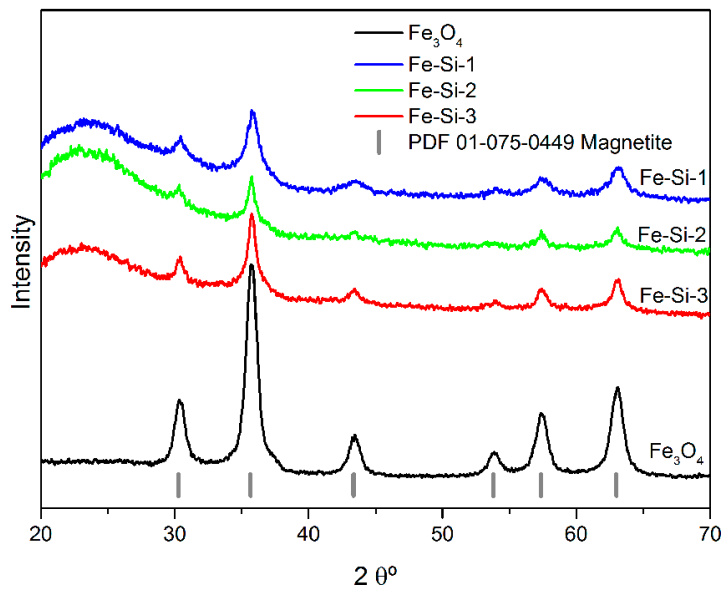

Figure 2. XRD patterns of samples $\mathrm{Fe}_{3} \mathrm{O}_{4}, \mathrm{Fe}-\mathrm{Si}-1, \mathrm{Fe}-\mathrm{Si}-2$, and Fe-Si-3.

After indexing the peaks of the core (sample $\mathrm{Fe}_{3} \mathrm{O}_{4}$ ), the cubic structure of magnetite was identified and found to be in good agreement with JCPDS card no. 089-096 $6^{27}$. The crystallite size of the core, determined by XRD from the broadening of the (311) diffraction peak using Scherrer's formula, was found to be $8 \mathrm{~nm}$. The crystal structure of the core did not change after coating with $\mathrm{SiO}_{2}$. However, the incorporation of silica was identified by the broad peak between $20^{\circ}$ and $30^{\circ}$.

Fig. 3 shows a typical TEM image of silica-coated magnetite obtained in sample Fe-Si-1.

In this figure, note the quasi-spherical $\sim 8 \mathrm{~nm}$ sized crystalline structures coated with an amorphous phase of heterogeneous thickness. Also, the lattice fringes $(2.9 \AA)$ in

Table 1. Summary of prepared samples.

\begin{tabular}{cccccc}
\hline Sample & $\mathrm{Fe}_{3} \mathrm{O}_{4}(\mathrm{~mol})$ & $\mathrm{SiO}_{2}(\mathrm{~mol})$ & phen $(\mathrm{mol})$ & $\mathrm{Eu}^{3+}(\mathrm{mol})$ & $\mathrm{Code}$ \\
\hline $\mathrm{Fe}_{3} \mathrm{O}_{4}$ & 0.0043 & - & - & - & $\mathrm{Fe}_{3} \mathrm{O}_{4}$ \\
$\mathrm{Fe}_{3} \mathrm{O}_{4} @ \mathrm{SiO}_{2}:$ phen:Eu & 0.0043 & 0.0013 & 0.0008 & 0.0002 & $\mathrm{Fe}-\mathrm{Si}-1$ \\
$\mathrm{Fe}_{3} \mathrm{O}_{4} @ \mathrm{SiO}_{2}:$ phen:Eu & 0.0043 & 0.0026 & 0.0016 & 0.0004 & $\mathrm{Fe}-\mathrm{Si}-2$ \\
$\mathrm{Fe}_{3} \mathrm{O}_{4} @ \mathrm{SiO}_{2}:$ phen:Eu & 0.0043 & 0.0013 & 0.0016 & 0.0004 & $\mathrm{Fe}-\mathrm{Si}-3$ \\
$\mathrm{SiO}_{2}:$ phen:Eu & - & 0.0013 & 0.0008 & 0.0002 & $\mathrm{SiO}_{2}: \mathrm{phen}^{: \mathrm{Eu}^{3+}}$ \\
\hline
\end{tabular}




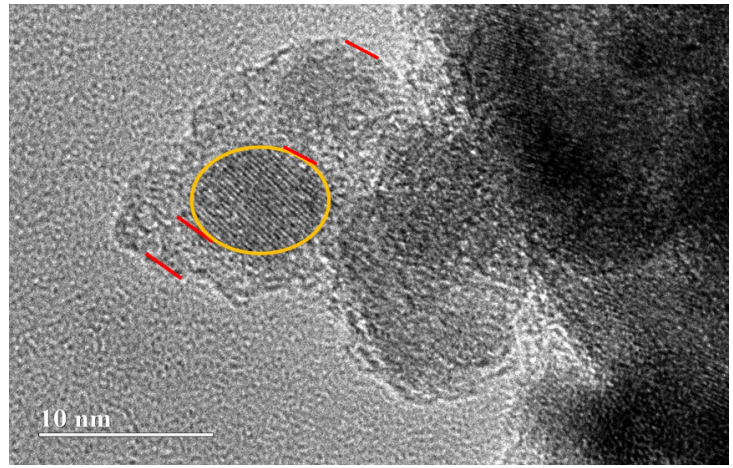

Figure 3. TEM image of Fe-Si-1.

Fig. 3 agree well with the distance between the (220) lattice planes, also observed in the XRD patterns, confirming the magnetite structure of these crystallite cores. Thus, based on chemical cross-linking, XRD measurements and TEM characterization, it can be concluded that the synthesis method employed here resulted in a polynucleated core-shell system composed of a magnetic core of $\mathrm{Fe}_{3} \mathrm{O}_{4}$ embedded in a silica shell ${ }^{28,29}$.

The magnetization curves of $\mathrm{Fe}_{3} \mathrm{O}_{4}, \mathrm{Fe}-\mathrm{Si}-1, \mathrm{Fe}-\mathrm{Si}-2$, and $\mathrm{Fe}-\mathrm{Si}-3$ powder samples measured room temperature are shown in Fig. 4.

Magnetization of the $\mathrm{Fe}_{3} \mathrm{O}_{4}$ core increased as the applied magnetic field was increased, tending to saturation at high magnetic fields $s^{16,20,27,28,30}$. The saturation magnetization calculated at the maximum magnetic field - was $48.9 \mathrm{emu} / \mathrm{g}$.
This is lower than bulk values but typical for nanosized magnetite, as was found by TEM measurements, and is probably due to cationic redistribution/defects and/or surface effects that affect the magnetization characteristics of nanosized grains. Moreover, this sample displayed features of superparamagnetism, such as negligible remanence and coercivity ${ }^{20}$, which were observed in the hysteresis loops. The inset of Fig. 4 shows magnetization only for the synthesized samples.

The magnetization of the core-shell samples decreased in proportion to the thickness of the silica coating, which is a diamagnetic material. However, all the coated samples showed the same magnetic behavior as the core. If the magnetization of samples Fe-Si-1, Fe-Si-2, and Fe-Si-3 were normalized by the saturation magnetization of the core, the estimated magnetic mass of these samples would be 18,11 , and $19 \%$, respectively.

The photoluminescence (PL) property of the samples was investigated, as indicated by the spectra shown in Fig. 5.

All the samples exhibit characteristic ${ }^{5} \mathrm{D}_{0} \rightarrow{ }^{7} \mathrm{~F}_{\mathrm{J}}(\mathrm{J}=0-4)$ $\mathrm{Eu}^{3+}$ emissions, i.e., they are luminescent materials. The hypersensitive ${ }^{5} \mathrm{D}_{0} \rightarrow{ }^{7} \mathrm{~F}_{2}$ emission is predominant, indicating that the $\mathrm{Eu}^{3+}$ ions occupy sites of low symmetry without inversion centers. On weak emissions of the higher ${ }^{5} \mathrm{D}_{\mathrm{J}}$ levels are visible, indicating efficient depopulation of the $T_{1}$ state through the antenna effect ${ }^{16,20,31}$. The photoluminescence emission intensity of the core-shell samples was compared based on the intensity of ${ }^{5} \mathrm{D}_{0} \rightarrow{ }^{7} \mathrm{~F}_{2}$. Samples Fe-Si-1, Fe$\mathrm{Si}-2$, and Fe-Si-3 were found to present 18,3 , and $3 \%$ of PL

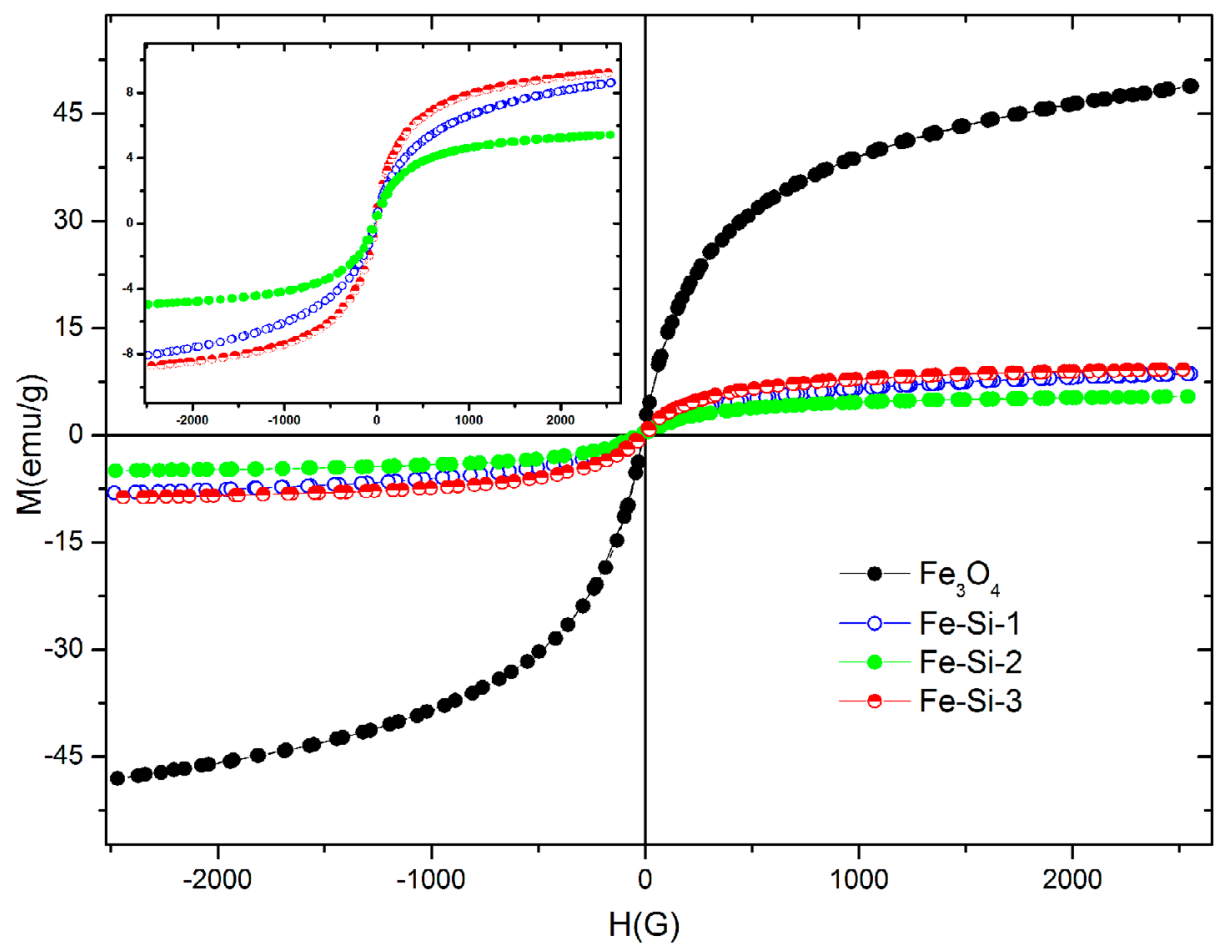

Figure 4. VSM data of samples $\mathrm{Fe}_{3} \mathrm{O}_{4}$, Fe-Si-1, Fe-Si-2, and Fe-Si-3. 


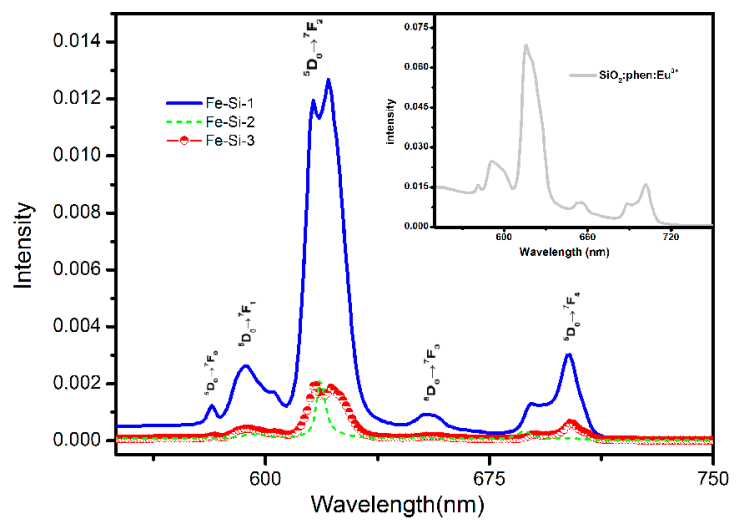

Figure 5. PL spectra of samples Fe-Si-1, Fe-Si-2, Fe-Si-3, and $\mathrm{SiO}_{2}$ :phen: $\mathrm{Eu}^{3+}$ (inset)

emission, respectively, relative to the PL emission intensity of $\mathrm{SiO}_{2}$ :phen: $\mathrm{Eu}^{3+}$ host.

The low intensity of Fe-Si-2 and Fe-Si-3 samples was attributed to the high concentration of $\mathrm{Eu}^{3+}$ ions. When many identical luminescent centers are present a "concentration quenching" may occur. Thus, the excitation energy is lost to the killer sites non-radiatively due to the increase in the number of luminescence centers ${ }^{32}$. The Fe-Si-2 and Fe-Si-3 samples are twice the amount of europium than sample Fe-Si-1.

\section{Conclusions}

Core-shell materials with magnetic and luminescent properties were synthesized in this study. The materials are composed of a crystalline magnetic core of $\mathrm{Fe}_{3} \mathrm{O}_{4}$ and a luminescent shell of amorphous $\mathrm{SiO}_{2}$. All the samples exhibit magnetization typical of nanosized magnetite and luminescent emission typical of europium(III) ions.

The performance of the Fe-Si-1 core-shell sample is promising. This sample has a crystalline magnetite structure, nanosized, superparamagnetic behavior and luminescent property. Samples Fe-Si-2 and Fe-Si-3 are superparamagnetic and luminescent, but sample $\mathrm{Fe}-\mathrm{Si}-1$ shows the best performance.

\section{Acknowledgment}

The authors thank the Brazilian research financing institutions CAPES and CNPq for their funding of this work.

\section{References}

1. Rezayan AH, Mousavi M, Kheirjou S, Amoabediny G, Ardestani MS, Mohammadnejad J. Monodisperse magnetite $\left(\mathrm{Fe}_{3} \mathrm{O}_{4}\right)$ nanoparticles modified with water soluble polymers for the diagnosis of breast cancer by MRI method. Journal of Magnetism and Magnetic Materials. 2016;420:210-217.
2. Revia RA, Zhang M. Magnetite nanoparticles for cancer diagnosis, treatment, and treatment monitoring: recent advances. Materials Today. 2016;19(3):157-168.

3. Nguyen DT, Kim KS. Controlled synthesis of monodisperse magnetite nanoparticles for hyperthermia-based treatments. Powder Technology. 2016;301:1112-1118.

4. Aono H, Nagamachi T, Naohara T, Itagaki Y, Maehara T, Hirazawa H. Synthesis conditions of nano-sized magnetite powder using reverse coprecipitation method for thermal coagulation therapy. Journal of the Ceramic Society of Japan. 2016;124(1):23-28.

5. Singh LH, Pati SS, Sales MJA, Guimarães EM, Oliveira AC, Garg VK. Facile Method to Tune the Particle Size and Thermal Stability of Magnetite Nanoparticles. Journal of the Brazilian Chemical Society. 2015;26(11):2214-2223.

6. Andrade AL, Fabris JD, Domingues RZ, Pereira MC. Current Status of Magnetite-Based Core@Shell Structures for Diagnosis and Therapy in Oncology Short running title: Biomedical Applications of Magnetite@Shell Structures. Current Pharmaceutical Design. 2015;21(37):5417-5433.

7. Li TJ, Huang CC, Ruan PW, Chuang KY, Huang KJ, Shieh DB, et al. In vivo anti-cancer efficacy of magnetite nanocrystal based system using locoregional hyperthermia combined with 5-fluorouracil chemotherapy. Biomaterials. 2013;34(32):78737883 .

8. Zhang L, Dong WF, Sun HB. Multifunctional superparamagnetic iron oxide nanoparticles: design, synthesis and biomedical photonic applications. Nanoscale. 2013;5(17):7664-7684.

9. Ferreira ADLB, Nóvoa PRO, Marques AT. Multifunctional Material Systems: A state-of-the-art review. Composite Structures. 2016;151:3-35.

10. Ma Q, Wang J, Dong X, Yu W, Liu G. Flexible Janus Nanoribbons Array: A New Strategy to Achieve Excellent Electrically Conductive Anisotropy, Magnetism, and Photoluminescence. Advanced Functional Materials. 2015;25(16):2436-2443.

11. Ma Q, Wang J, Dong X, Yu W, Liu G. Magnetic-upconversion luminescent bifunctional flexible coaxial nanoribbon and Janus nanoribbon: One-pot electrospinning preparation, structure and enhanced upconversion luminescent characteristics. Chemical Engineering Journal. 2015;260:222-230.

12. Bi F, Dong X, Wang J, Liu G. Coaxial electrospinning preparation and properties of magnetic-photoluminescent bifunctional $\mathrm{CoFe}_{2} \mathrm{O}_{4} @ \mathrm{Y}_{2} \mathrm{O}_{3}:$ Eu $^{3+}$ coaxial nanofibers. Journal of Materials Science: Materials in Electronics. 2014;25(10):4259-4267.

13. Ma Q, Yu W, Dong X, Wang J, Liu G. Janus nanobelts: fabrication, structure and enhanced magnetic-fluorescent bifunctional performance. Nanoscale. 2014;6(5):2945-2952.

14. Ma Q, Wang J, Dong X, Yu W, Liu G, Xu J. Electrospinning preparation and properties of magnetic-photoluminescent bifunctional coaxial nanofibers. Journal of Materials Chemistry. 2012;22(29):14438-14442.

15. Rice KP, Russek SE, Geiss RH, Shaw JM, Usselman RJ, Evarts ER, et al. Temperature-dependent structure of Tb-doped magnetite nanoparticles. Applied Physics Letters. 2015;106(6):062409. 
16. Gowd GS, Patra MK, Mathew M, Shukla A, Songara S, Vadera SR, et al. Synthesis of $\mathrm{Fe}_{3} \mathrm{O}_{4} @ \mathrm{Y}_{2} \mathrm{O}_{3}:$ Eu$^{3+}$ core-shell multifunctional nanoparticles and their magnetic and luminescence properties. Optical Materials. 2013;35(9):1685-1692.

17. McCarthy JE, Prina-Mello A, Rakovich T, Volkov Y, Gun'ko YK. Fabrication and characterization of multimodal magnetic - fluorescent polystyrene nanowires as selective cell imaging probes. Journal of Materials Chemistry. 2011;21(37):1421914225 .

18. Zhang Y, Das GK, Xu R, Tan TTY. Tb-doped iron oxide: bifunctional fluorescent and magnetic nanocrystals. Journal of Materials Chemistry. 2009;19(22):3696-3703.

19. De Silva CR, Smith S, Shim I, Pyun J, Gutu T, Jiao J, et al. Lanthanide(III)-Doped Magnetite Nanoparticles. Journal of the American Chemical Society. 2009;131(18):6336-6337.

20. Fan H, Li B, Feng Y, Qiu D, Song Y. Multifunctional Fe $\mathrm{O}_{4} @$ $\mathrm{SiO}_{2} @ \mathrm{GdVO}_{4}: \mathrm{Eu}^{3+}$ core-shell nanocomposite for a potential drug carrier. Ceramics International. 2016;42(11):13326-13330.

21. Huang S, Chen Y, Liu B, He F, Ma P, Deng X, et al. Synthesis of magnetic and upconversion nanocapsules as multifunctional drug delivery system. Journal of Solid State Chemistry. 2015;229:322-329.

22. Hu X, Wang M, Miao F, Ma J, Shen H, Jia N. Regulation of multifunctional mesoporous core-shell nanoparticles with luminescence and magnetic properties for biomedical applications. Journal of Materials Chemistry B. 2014;2(16):2265-2275.

23. Rosa ILV, de Sousa Filho PC, Neri CR, Serra OA, de Figueiredo AT, Varela JA, et al. Synthesis and Study of the Photophysical Properties of a New Eu3+ Complex with 3-Hydroxypicolinamide. Journal of Fluorescence. 2011;21(4):1575-1583.

24. Li C, Ma C, Wang F, Xi Z, Wang Z, Deng Y, et al. Preparation and biomedical applications of core-shell silica/magnetic nanoparticle composites. Journal of Nanoscience and Nanotechnology. 2012;12(4):2964-2972.
25. Drummond AL, Feitoza NC, Duarte GC, Sales MJ, Silva LP, Chaker JA, et al. Reducing size-dispersion in one-pot aqueous synthesis of maghemite nanoparticles. Journal of Nanoscience and Nanotechnology. 2012;12(10):8061-8066.

26. Liu L, Gill SK, Gao Y, Hope-Weeks LJ, Cheng KH. Exploration of the use of novel $\mathrm{SiO}_{2}$ nanocomposites doped with fluorescent $\mathrm{Eu}^{3+} /$ sensitizer complex for latent fingerprint detection. Forensic Science International. 2008;176(2-3):163-172.

27. Wu W, Wu Z, Yu T, Jiang C, Kim WS. Recent progress on magnetic iron oxide nanoparticles: synthesis, surface functional strategies and biomedical applications. Science and Technology of Advanced Materials. 2015;16(2):023501.

28. Chae HS, Kim SD, Piao SH, Choi HJ. Core-shell structured $\mathrm{Fe}_{3} \mathrm{O}_{4} @ \mathrm{SiO}_{2}$ nanoparticles fabricated by sol-gel method and their magnetorheology. Colloid and Polymer Science. 2016;294(4):647-655.

29. Shi W, Lu D, Wang L, Teng F, Zhang J. Core-shell structured $\mathrm{Fe}_{3} \mathrm{O}_{4} @ \mathrm{SiO}_{2} @ \mathrm{CdS}$ nanoparticles with enhanced visible-light photocatalytic activities. RSC Advances. 2015;5(128):106038106043.

30. Stefan M, Leostean C, Pana O, Soran ML, Suciu RC, Gautron E, et al. Synthesis and characterization of $\mathrm{Fe}_{3} \mathrm{O}_{4} @ \mathrm{ZnS}$ and $\mathrm{Fe}_{3} \mathrm{O}_{4} @ \mathrm{Au} @ \mathrm{ZnS}$ core-shell nanoparticles. Applied Surface Science. 2014;288:180-192.

31. Kim BC, Lee CY, Song YH, Kang SY, Suh KS, Lee NY, et al. Luminescence Properties of Pigment-Coated $\mathrm{Y}_{2} \mathrm{O}_{3}:$ Eu Red Phosphor with $\alpha-\mathrm{Fe}_{2} \mathrm{O}_{3}$ by Different Coating Methods and Various Exciting Energy Source. Japanese Journal of Applied Physics. 2002;41(Pt 1):2066-2073.

32. Alaparthi SB, Lu L, Tian Y, Mao YB. Europium doped lanthanum zirconate nanoparticles with high concentration quenching. Materials Research Bulletin. 2014;49:114-118. 